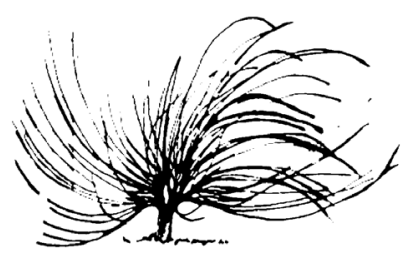

\title{
Escuelas para la justicia social: experiencias de liderazgo en dos centros educativos costarricenses
}

\author{
Virginia Cerdas-Montano ${ }^{1}$ \\ Universidad Nacional \\ Costa Rica \\ norma.cerdas.montano@una.cr \\ José Antonio García-Martínez $z^{2}$ \\ Universidad Nacional \\ Costa Rica \\ jose.garcia.martinez@una.cr \\ Charles L. Slater ${ }^{3}$ \\ California State University \\ United States of America \\ charles.slater@csulb.edu
}

\begin{abstract}
Resumen
El liderazgo para la justicia social es un tema que ha cobrado relevancia en los espacios de diálogo vinculados a temas educativos, en muchos contextos alrededor del mundo y Costa Rica no es la excepción. El objetivo de este estudio es el análisis en relación con esta temática, así como el aporte
\end{abstract}

\section{(c) (i) $(5)$}

Recibido: 30 de enero de 2018. Aprobado: 24 de setiembre de 2018.

http://dx.doi.org/10.15359/rep.13-2.8

1 Doctora en Educación con especialidad en Mediación Pedagógica. También cuenta con una especialidad en Gestión Educativa con énfasis en liderazgo, ejerce como académica e investigadora en la División de Educación para el Trabajo (CIDE) de la Universidad Nacional, Costa Rica.

2 Máster en Educación y Tecnologías con énfasis en Investigación por la Universidad Oberta de Catalunya. Ejerce como docente e investigador en la División de Educación para el Trabajo (CIDE) de la Universidad Nacional, Costa Rica.

3 Professor of Educational Leadership at California State University Long Beach (CSULB). Former professor, Texas State University San Marcos. Former superintendent of schools in Texas and Massachusetts. Ph. D. University of Wisconsin-Madison. 
de ideas para los educadores en formación y en ejercicio; igualmente, para las personas que dirigen el rumbo en materia de políticas educativas del país. Desde un enfoque cualitativo, se implementa el protocolo de entrevista de la Red Internacional de Desarrollo de Liderazgo (ISLDN), que surge como parte de las reflexiones en la Convención de la University Council for Educational Administration (UCEA) en el 2008, el cual está conformado por cinco preguntas. Los sujetos de análisis son dos directivos escolares, concretamente del nivel de preescolar público y de una unidad pedagógica privada. Los resultados sugieren un estilo de liderazgo democrático con algunas características de transformacional, centrados en aspectos de la justicia social como reconocimiento y capacidades de las personas. Además, se hallan coincidencias, en ambos casos, con los aportes teóricos revisados basados en las cuatro categorías de justicia social: económica, cultural, asociativa y para el desarrollo.

Palabras claves: liderazgo, gestión, justicia social y educación.

\begin{abstract}
Leadership for social justice is an issue that has gained relevance for professionals in education in many contexts around the world and Costa Rica is no exception. The objective of this study is the analysis around this theme, as well as the contribution of ideas both for practicing educators as well as those in training and for those who direct national educational policies. The interview protocol of the International Study of Leadership Development Network (ISLDN) and the Convention of the University Council for Educational Administration (UCEA) in the 2008 were used to interview two school administrators in a public preschool and a private multi-grade school. The results suggest a style of democratic and transformational leadership centered on aspects of social justice such as recognition and development of others' capabilities. There were a number of similarities between the two cases related to four broad categories of social justice: economic, cultural, associative and developmental.
\end{abstract}

Keywords: leadership, management, social justice and education. 


\section{Introducción y objetivos}

$\mathrm{E}$ 1 presente trabajo forma parte de una investigación de mayor envergadura que se está realizando en el marco de un proyecto desde la Universidad Nacional de Costa Rica, con el nombre de "Liderazgo en las organizaciones educativas costarricenses para la justicia social: tendencias y desafíos". El objetivo de este estudio es el análisis del liderazgo de dos líderes en justicia social, ambos directores de centros educativos costarricenses, concretamente del nivel de preescolar el primero de ellos y una unidad pedagógica (brinda una oferta educativa de primaria y secundaria completa).

Específicamente, con este trabajo se pretende conocer las concepciones de justicia social, cómo se forman los líderes de esta y cuáles son los obstáculos que encuentran en sus prácticas, lo que permite un acercamiento desde la realidad de los directivos, en un contexto dinámico y complejo (Barquero y Montero, 2013; Garbanzo y Orozco, 2007). A su vez, se desarrolla una revisión teórica para comprender a profundidad esas dinámicas que se viven a diario en los centros educativos. La comprensión de estas dinámicas desde la perspectiva de la justicia social es de gran importancia para la formación de administradores educativos, ya que en estos espacios de aprendizaje se pueden encontrar claves que permitan apoyar y mejorar los procesos educativos.

\section{Liderazgo y justicia social}

La justicia social como labor intencionada en los centros educativos suscita, según Murillo y Hernández (2014), "la creación de comunidades de profesionales de aprendizaje, de promover la colaboración entre las escuelas y la familia, y de expandir el capital social de los estudiantes" (p. 13), favoreciendo, acorde con estos autores, una concepción de justicia social, que integra tres elementos primordiales: redistribución, reconocimiento y representación.

Uno de los cuestionamientos que generan Murillo y Hernández (2014), en relación con el tema del liderazgo en las escuelas, es precisamente el que se refiere al papel que juegan los centros educativos en la búsqueda de justicia social, para mejorar las condiciones y oportunidades del estudiantado. En todo caso, la escuela puede convertirse en reproductora y legitimadora de las injusticias o ser dinamizadora de cambios sociales. 
En este sentido, autores como Bourdieu, Passeron, Melendres y Subirats (1981) asumen la escuela como una entidad reproductora de las desigualdades, que perpetúa el orden social preestablecido. Presuponen que, para mantener el orden social, es necesario un instrumento regulador como la escuela, al cual se le otorga la potestad, a través del Estado, de regular la titulación, lo que trae consigo una regulación social de estatus y posibilidades de participación. Como antítesis de esta postura, los mismos autores asumen cuatro premisas básicas, las cuales sugieren que todas las escuelas son un universo de posibilidades, no todas se comportan como legitimadoras de las desigualdades y algunas funcionan como motores de cambio social. Otra premisa es que, si una escuela no se propone trabajar por la justicia social, inevitablemente se convierte en una reproductora de injusticias. En esta misma línea, manifiestan que una escuela que logra instalar una cultura colaborativa, entre sus docentes, tiene mayores posibilidades de trabajar para la justicia social. Finalmente, la cuarta premisa menciona que el líder del centro escolar es clave como eje dinamizador de los procesos que acerquen a un trabajo intencionado desde y por la justicia social (Bourdieu et al., 1981).

Por otro lado, Montané (2015) hace un recorrido histórico del concepto justicia social y lo vincula con la educación, resumiendo que en el contexto actual hay términos que caracterizan la justicia social desde los procesos educativos: legitimidad, dignidad, justicia, libertad, reconocimiento, participación y capacidad. Expresa esta autora que la justicia social constituye un principio de vida, en el cual está presente la intervención del Estado que legitima la "justicia" asociada a los valores. En esta misma línea, aporta que se requiere una actitud tanto ética como moral individual y colectiva de respeto y reconocimiento, el cual empodera la dignidad humana, vinculada también a la igualdad.

Igualmente, Montané (2015) refiere que el principio socioeducativo requiere que los centros educativos no solo tengan nociones de justicia social válidas, sino que sean vivenciadas en todos los espacios de formación. Esta premisa se vincula con el estilo de liderazgo que requiere el centro educativo, por lo que algunos autores coinciden en liderazgos participativos, democráticos, que favorezcan los procesos de construcción colaborativos.

Nussbaum (2010) indica que el ordenamiento social es justo o injusto no por ser objeto de un contrato original, sino más bien tiene vinculación directa con los procesos de formación a los cuales las 
personas tienen acceso y que, por tanto, puedan desarrollar sus capacidades básicas para llevar una vida plena, centradas en sus necesidades y características propias. De estas investigaciones profundizadas por Nussbaum (2010), se pueden identificar once capacidades básicas: vida, salud física, integridad corporal, sentidos, imaginación y pensamiento, emociones, juego, razón práctica, afiliación, control sobre el propio entorno y respeto a otras especies. En relación con estas capacidades asociadas a la justicia social, se denota una clara ampliación del concepto y de la vivencia en los entornos escolares.

En la misma línea del desarrollo de capacidades como elemento clave para la justicia social, Dubet (2005, citado por Bolívar, 2011) se refiere a la necesidad de cambiar la norma de la escuela obligatoria, no con la intención de disminuirla, sino para conceder otra función; trascender los programas que muy pocos estudiantes comprenden, por otro programa al que tienen derecho, el cual propicie el desarrollo de sus capacidades y que así puedan alcanzar una cultura común, cuya excelencia sea parte del diario quehacer de la escuela.

Continuando con esta misma perspectiva teórica, Murillo, Krichesky, Castro y Hernández (2010) aportan un elemento más que enriquece la concepción de justicia social, la inclusión. Este enfoque inclusivo, recalca la necesidad de una transformación del sistema escolar desde su estructura física, curricular, visión, estilos de enseñanza y de liderazgo, con el fin de que celebre la diversidad y ofrezca una propuesta para todos, eliminando cualquier elemento de exclusión, ya sea por etnia, religión, clase social, género, orientación del deseo sexual, lengua materna o cultura de origen. La educación inclusiva requiere el marco ético que garantice el acceso, la participación y el aprendizaje para todos, partiendo desde su propio contexto social y cultural.

Otro de los elementos sustantivos en este referente conceptual lo constituye el liderazgo, pero no cualquier estilo de leste, sino aquel que favorezca procesos participativos que contribuyan a establecer una cultura colaborativa. En este sentido, Murillo et al. (2010) indican, sobre los directores escolares, que, además de tener el potencial para frenar o generar medidas de inclusión, "un buen liderazgo requiere de saber potenciar una cultura de la inclusión para la justicia social partiendo de supuestos, principios, creencias y valores que se vinculen con la acción pedagógica del centro" (p. 174). 
El estilo de liderazgo, según algunos autores consultados (Contreras y Barbosa, 2013; Fernández y Hernández, 2013; Molano, 2016), refiere principalmente a un estilo adaptativo que puede variar en su forma, pero no en su esencia, la cual está determinada por la justicia social de manera intencionada.

Cribb y Gewirtz (2003) mencionan tres tipos de justicia social. La primera refiere a la justicia económica que pretende garantizar la igualdad de oportunidades sin importar raza, credo o condición de género. La justicia cultural promueve el reconocimiento del individuo como parte de un contexto sociocultural, con valores propios de su grupo social. La justicia asociativapromulga la participación de todos y tiene relación estrecha con los contextos democráticos. Finalmente, Woods (2005) agregó un cuarto tipo de justicia social que refiere la justicia para el desarrollo, la cual tiene estrecha relación con las capacidades de las personas.

La categorización de justicia social que refieren Cribb y Gewirtz (2003) tiene relación directa con el liderazgo de los directivos escolares, ya que los contextos educativos deben ser por excelencia promotores y defensores de tal justicia. La labor de los educadores debe tener una amalgama firme en la búsqueda de la justicia social, ya que a través de la educación es que los ciudadanos tienen posibilidades de mejorar su condición de vida.

Otros autores como Montané (2015) comparten estos postulados y puntualizan que las teorías de la justicia constituyen en esencia los términos "legitimidad, dignidad, justicia, libertad, reconocimiento, participación y capacidad" (p. 3).

Uno de los retos para la humanidad es precisamente la justicia social. La exclusión social, por género, etnia, credo u orientación del deseo sexual, ha contribuido a que algunos grupos de seres humanos hayan sido invisibilizados. Es por ello que legitimar los contextos culturales, sus valores y creencias es sustantivo para dignificar a las personas que han sido marginadas.

Freire (2005) ha sido uno de los autores más reconocidos, en el ámbito latinoamericano, en defensa de los sectores excluidos de la sociedad, proponiendo que mediante la educación se puedan cerrar brechas sociales y alcanzar niveles de justicia más inclusivos y representativos, con los que se dignifique a las personas y se legitimen los contextos y saberes. 
McKenzie et al. (2008) aportan en sus investigaciones la necesidad de una participación democrática e inclusiva. La justicia social tiene muchas perspectivas desde las cuales se puede abordar; sin embargo, en este artículo interesa una concepción inclusiva, representativa, que promueva las capacidades de las personas para una participación democrática con la que se hagan valer sus derechos y puedan tener un justo acceso a las posibilidades de mejoramiento de su calidad de vida.

\section{Metodología}

El presente artículo forma parte de una investigación de mayor envergadura que se realiza como parte de la Red Internacional de Desarrollo de Liderazgo (ISLDN), iniciada en el 2008 y que ha sido patrocinada conjuntamente por la Sociedad de Administración y Administración de Liderazgo Educativo Británico (BELMAS) y el Consejo Universitario de Administración Educativa (UCEA).

Desde una perspectiva inductiva y un enfoque cualitativo, la indagación se aborda desde un paradigma interpretativo, ya que parte de una interpretación subjetiva, así como de los significados que generan las personas participantes (Bisquerra, 2014). El alcance del estudio es de tipo exploratorio-descriptivo (Hernández, Fernández y Baptista, 2010), ya que no existen trabajos similares en el ámbito nacional, y, por otro lado, se describe el significado que los sujetos de análisis otorgan al liderazgo en y para la justicia social.

Teniendo en cuenta aspectos tanto teóricos como metodológicos, el diseño seleccionado es narrativo, pues se pretende describir y analizar la experiencia de dos líderes en justicia social, donde cobra interés tanto la persona como su entorno (Hernández, et al. 2010), y, de igual modo, el diseño se considera de tópicos (Mertens, 2005, citado por Hernández et al., 2010), ya que se enfoca en una temática particular.

A pesar de que no existen procesos predeterminados para implementar este tipo de estudio (Hernández et al., 2010), se propone (ver figura 1) las siguientes fases en las cuales se ha estructurado el proceso de investigación. En primer lugar, se plantea un problema y objetivos orientativos; en una segunda fase, se selecciona a la persona informante y se visita el centro educativo que dirige, para contextualizar su historia, así como para buscar antecedentes históricos del contexto; en la tercera parte, se recogen los datos a través de una entrevista en el centro 
educativo; en la cuarta, se elabora un primer informe y se discute con la persona informante sobre los datos recogidos y un primer análisis; finalmente, en la última fase y de acuerdo con la devolución, se realiza un análisis más exhaustivo y la redacción del informe final.

\section{Figura 1.}

\section{Fases del diseño de investigación.}

\section{FASE 1: Planteamiento orientativo del problema}

FASE 2: Selección de participantes e inmersión al campo

FASE 3: Recolección de datos

FASE4: Elaboración del informe y revisión con los participantes

FASE 5: Análisis y elaboración de informe final.

\section{El contexto del centro de preescolar}

El primer centro educativo pertenece al nivel preescolar; tiene un total de 202 estudiantes y 21 personas laborando en él. La población es heterogénea y proviene de barrios de la zona sur de San José. Principalmente, el estudiantado viene de familias con limitaciones socioeconómicas, pero con la disposición de brindar una mejor educación a sus hijos. En cuanto a la comunidad alrededor del centro, no es tradicional, la mayoría de estudiantes son de lugares aledaños, pagan microbús o se benefician con los convenios ${ }^{4}$ existentes para su traslado. Igualmente, muchas de las familias del estudiantado son inmigrantes o incluyen menores con nacionalidad costarricense, pero de padres extranjeros, especialmente nicaragüenses y colombianos.

La comunidad estudiantil que vive en el entorno se hospeda en cuarterías y pertenece a familias consideradas como población flotante,

4 El centro educativo tiene diferentes convenios con diversas instituciones como Obras del Espíritu Santo, Ejército de Salvación, Clínica Bíblica, entre otros. 
ya que, si consiguen un lugar más barato para vivir, abandonan el vecindario y, por ende, el centro educativo.

La oferta educativa se diferencia de otros centros educativos de preescolar aledaños (pero pertenecientes, de igual manera, al MEP), en ampliar el desarrollo de capacidades del estudiantado, a través de formación en danza, artes marciales, deportes, capoeira, inglés, informática, entre otros, que la población demanda. Aunado a lo anterior, se brinda servicio gratuito de odontología y comedor escolar. Cabe destacar que la apertura de estos procesos que enriquecen el currículo escolar ha sido gestionada por la directora del centro junto a su equipo de trabajo.

Igualmente, es relevante indicar que se ofrece atención de un equipo interdisciplinario conformado por orientadora, trabajadora social, psicóloga y terapista del lenguaje, cuya conformación ha sido posible por la gestión de convenios con universidades públicas.

Finalmente, se destaca la existencia de un centro de acopio manejado por el estudiantado, que, aunado a una mini granja, fortalece la conciencia ambiental y social.

La directora del centro (informante 1) inició hace 28 años como educadora, lleva laborando 27 en puestos de dirección y 14 en el centro educativo de preescolar donde se contextualiza el presente estudio.

\section{El contexto de la unidad pedagógica}

El centro educativo se ubica en Barrio Escalante, uno de los barrios más antiguos de la capital de Costa Rica. Es de fácil acceso y se caracteriza por ser una zona urbana y de alto tránsito vehicular. En el corazón de San José, este centro educativo recibe estudiantes de la Gran Área Metropolitana, que han sido excluidos escolarmente y tienen problemas de motivación y rendimiento académico. Es un espacio para celebrar la diversidad y brindar una oportunidad a las familias que no encuentran opción en el sistema público o privado, pero que no se dan por vencidas, porque creen que la educación es el puente para una mejor calidad de vida.

El centro educativo es privado; sin embargo, debe responder a las políticas vigentes del sistema educativo costarricense. Fue creado en 1994 con el objetivo de brindar una oferta educativa que atienda necesidades de estudiantes excluidos del sistema educativo y que requieran 
procesos alternativos para sus diversas necesidades. Para ello, se plantea una atención individualizada que permita gestionar adecuaciones curriculares, las cuales respondan de manera concreta al desarrollo de las capacidades de cada estudiante.

La población que reciben viene, en muchos casos, con problemas de autoestima por el rechazo y la exclusión escolar. En este centro educativo, se enfocan en el estudiante y su potencial, atendiendo sus necesidades de manera individual.

La población atendida se ubica entre primaria y secundaria, actualmente es de 690 estudiantes. Se trabaja en turno de mañana, tarde y hace dos años abrieron un horario especial para estudiantes que sobrepasan los 18 años.

Centran la atención del estudiante en lo socioafectivo y promueven una metodología que se denomina aula estructurada, la cual brinda un protocolo de atención a la diversidad, legitimando al estudiante en su microcultura estudiantil, sin intentar que su perfil sea generalizado, sino más bien particular. Esto favorece que el aprediz se sienta en un ambiente de inclusión y aceptación.

Refiere el director (informante 2): "no somos educación especial, sino especializada, el punto medio entre la educación ordinaria y la especial".

\section{Técnicas de recolección de datos}

La técnica de recolección de datos se lleva a cabo a través de una encuesta, específicamente, se utiliza la entrevista como instrumento de recolección de datos. Desde el punto de vista estructural, la herramienta es de tipo semiestructurado (Hernández et. al, 2010). La entrevista pertenece a un protocolo establecido por la Red Internacional de Desarrollo de Liderazgo (ISLDN). Se estructura a través de cuatro grandes preguntas, así como de un apartado inicial de preguntas generales. La duración fue de aproximadamente 90 minutos; fue grabada y posteriormente transcrita en digital, al igual que revisada por la persona participante, como parte de los criterios para el estudio. Este protocolo de entrevista está siendo utilizado en países de todo el mundo para explorar las siguientes interrogantes: 
1. ¿Cómo dan sentido los líderes de justicia social a la justicia social?

2. ¿Qué hacen los líderes de justicia social?

3. ¿Qué factores ayudan e impiden el trabajo de los líderes de la justicia social?

4. ¿Cómo aprendieron los líderes de justicia social a convertirse en líderes de justicia social?

\section{Resultados}

A continuación, se muestran los resultados obtenidos de las entrevistas. Para una mejor estructura de estos, se exponen las respuestas de ambos directores para cada una de las áreas.

\section{Sentido de los líderes de justicia social sobre la justicia social}

Sobre la concepción de justicia social, la directora de preescolar destaca tres elementos primordiales: las oportunidades (justicia económica), el acceso (justicia asociativa) y el desarrollo de las capacidades de sus estudiantes (justicia para el desarrollo). Para esta profesional, la justicia social es "que todos tengamos las mismas oportunidades y que las condiciones de acceso para satisfacer nuestras necesidades sean reales, que no haya para unos y para otros no. Todos deberíamos tener acceso a todos los servicios, a cubrir todas nuestras necesidades" (informante 1). En estas ideas sobre justicia social, se denota que las oportunidades y el acceso son co-sustantivos para ella. Sin embargo, también expresa que "debemos enseñarles a los niños las dos caras de la moneda, ellos vienen de ambientes restringidos y hay que mostrarles que se puede vivir en condiciones diferentes" (informante 1). Este aporte de la directora se asocia con el desarrollo de capacidades, en el tanto los estudiantes puedan utilizar la educación como herramienta para superar sus condiciones actuales y que, a través de esta, se puedan lograr otras oportunidades que favorezcan la superación de contextos de maltrato y pobreza.

En el caso del director de la unidad pedagógica, expresa que la justicia social "no debe ser concebida en base a leyes o fundamentos, debe ser algo tangible, que tengan derecho dentro de región, un espacio geográfico para tener los mismos derechos, en educación, de vivienda, erradicar pobreza, accesibilidad al empleo, salud, paz social, desarrollo 
humano y calidad de vida para todos" (informante 2). Se refleja una percepción de la justicia social desde un enfoque de reconocimiento, en donde la distribución de la riqueza es importante. Además, se revela un enfoque territorial, en el que predomina una distribución de recursos para que todas las personas puedan acceder una mejor calidad de vida.

Se contempla un abordaje integral de salud y paz social mediante la educación, coincidiendo con lo expresado por Nussbaum (2010) sobre justicia social, el cual aboga por el ordenamiento social que favorece el desarrollo de las capacidades básicas de las personas, para poder llevar una vida plena, que satisfaga sus necesidades y características propias.

\section{Accionar de los líderes de justicia social}

La directora de preescolar se refiere a las acciones que desarrolla el centro educativo para la justicia social, centrándose en algunos elementos predominantes de la justicia asociativa: participación democrática, servicios complementarios, modelar el liderazgo, trabajo en equipo y misión clara del rumbo de la institución.

En este centro educativo, tienen cabida acciones que constituyen su cultura organizacional, ya que su dirigente indica: "Todas las mañanas hacemos oración juntos, cantamos el himno nacional y cantamos el de la institución, compartimos buenas noticias. En esta actividad se incluyen tanto a los estudiantes como a las familias" (informante 1). Se establecen espacios que favorecen la identidad del centro educativo, sus creencias, valores y costumbres, que se construyen con la acción repetitiva y permiten, además, un sentido de pertinencia facilitador de otro tipo de procesos colaborativos.

Otro de los aportes que hace la directora es que "Todos los días hay acceso a merienda, para todos." Esto hace explícita la necesidad de cubrir una condición nutricional del estudiantado, asociada con la población en condiciones de vulnerabilidad que se recibe en el centro educativo. Agrega que existen algunos servicios complementarios, entre los cuales se destaca que "Los niños tienen mucho problema odontológico, para los cuales hemos logrado establecer que los atiendan y que se les apoye para cambiar hábitos de higiene bucodental" (informante 1).

Por otro lado, la directora genera acciones para enseñar con el ejemplo, el estudiantado necesita que constantemente se le muestren normas de cortesía y de comunicación. En este sentido, la encargada 
expresa que hay que "modelar con el ejemplo, decir una cosa y hacer otra no es bueno. Tenemos que ser congruentes" (informante 1). En este sentido, se percibe un estilo de liderazgo basado en principios y valores comunes para el centro educativo.

Otra de las acciones que hace referencia a la justicia social es el trabajo en equipo; al respecto menciona la directora: "Aquí conformamos un equipo de trabajo, en este equipo la directora tiene imagen de autoridad y respeto, pero no de diferente, al resto del equipo" (informante 1). Continúa diciendo que "La conformación de un equipo es clave, no se puede separar docentes de conserjes o cocineras, todos tenemos una función importante, trabajamos por los mismos objetivos; por los niños" (informante 1). Se denota la inclusión del personal como parte de un trabajo colaborativo, en donde se valora cada una de las funciones que se ejercen en el centro educativo. Además, se une un elemento clave como una misión clara de la institución: el trabajar con y para los estudiantes.

Como parte del accionar en un contexto democrático, llama la atención lo que comenta la informante 1: "No es lo que diga el director, la mejor idea es la que nos va a funcionar, estamos en función del bienestar de los estudiantes".

El director de la unidad pedagógica se refiere a las acciones que desarrollan en el centro educativo para la justicia social y da mucha importancia al trabajo en equipo para poder llevar a la realidad de las aulas una visión conjunta que permita crear una cultura institucional, en donde los estudiantes sean el centro de atención y el docente esté al servicio de ellos. Expresa que lo primero que hace en el centro educativo es "crear ideas poderosas, porque si no, no se puede cambiar el mundo" (informante 2).

Ese segundo informante refiere que el estudiantado no tiene las mismas capacidades y, por ello, se debe atender en el salón de clases con diversas propuestas metodológicas que permitan ir avanzando con cada uno, de acuerdo con sus características. Se dan talleres, espacios de atención individual. "No se permiten etiquetas para los estudiantes" (informante 2), cada uno es simplemente un ser humano con sus propias necesidades.

Así mismo, con los docentes se desarrollan talleres, conversatorios para poner proyectos comunes que permitan una misma visión y dirección de la cultura organizacional. Esto permite dar seguimiento y evaluar lo que se plantea como meta. "Hay que hacer ajustes internos y volvernos líderes proactivos, para que las cosas sucedan" (informante 
2). Continúa diciendo "se educa para el mundo, no para vivir en un aula o cuatro paredes, si no son personas productivas lo que obtienen es empleos terciarios, se marcan clases sociales. Cada vez que un chico obtenga su título, tiene éxito, es menos exclusión o pobreza social" (informante 2).

Lo expresado por el director tiene respaldo desde la perspectiva teórica, de Murillo et al. (2010), quienes aportan que el sistema educativo debe transformarse en todos los ámbitos, en lo físico, lo curricular, la visión y los estilos de enseñanza. Además, sus miembros se deben convertir en líderes que celebren la diversidad y piensen propuestas conjuntas para responder a las necesidades de los estudiantes.

\section{Factores que ayudan al trabajo de los líderes de la justicia social}

Seguidamente, se cuestiona a la directora de preescolar sobre los factores que facilitan el trabajo para la justicia social en su centro educativo. Se destacan el ambiente organizacional, el seguimiento y la claridad en el perfil de salida del estudiantado.

Se menciona que "el clima organizacional permite compartir valores, se favorece comunicación y confianza" (informante 1), refiere a valores comunes con los cuales se moviliza el accionar del centro educativo. Igualmente, aduce: "hacemos actividades para medir si los valores que tenemos institucionalmente establecidos se cumplen" (informante 1). Existen mecanismos de seguimiento, lo que destaca una intención clara y concreta por vivenciar los valores, hecho que Bolívar (2015) refiere como una de las prácticas deseadas en los centros educativos para la justicia social.

En este sentido, afirma la directora que "hay que tener claro el tipo de personas que estamos formando, ¿qué tipo de ciudadano queremos formar? Es clave la formación integral, es dejar de lado que transmitimos conocimientos, porque lo más importante es que la formación permita al estudiante el desarrollo de habilidades para entenderse a sí mismo, a los demás para trabajo en equipo, etc., son habilidades que no se aprenden con una computadora. Desarrolla habilidades para la vida que se puedan llevar a la práctica" (informante 1). Esta idea es concordante con lo expresado por Nussbaum (2010), quien define que las once capacidades para la justicia social son precisamente vida, salud física, integridad corporal, sentidos, imaginación y pensamiento, 
emociones, juego, razón práctica, afiliación, control sobre el propio entorno y respeto a otras especies.

En lo referente al director de la unidad pedagógica, este menciona que uno de los factores que ayudan a la justicia social es "la forma de ser del costarricense, la idiosincrasia, son personas que pueden recibir un consejo, que acatan directrices básicas para rescatar niños del fracaso escolar" (informante 2). Además, refiere que existen organizaciones que apoyan propuestas diferentes, "es solo tocar las puertas indicadas para que se abran" (informante 2). Otro de los factores que favorecen es la paz social que se tiene en Costa Rica, "no solo que no haya guerra, sino que haya comida en el plato" (informante 2), haciendo hincapié en la democracia vivida en Costa Rica hace más de 100 años.

\section{Factores que impiden el trabajo de los líderes de la justicia social}

En cuanto a los factores que obstaculizan la justicia social en el centro educativo, según la directora de preescolar, pueden considerarse la vocación docente y la participación de las familias en los procesos de formación.

Respecto a los obstáculos que se presentan, la directora menciona: "nos afecta el tipo de profesional que llega, se siente cuando hay vocación, la pasión en todo lo que uno hace, si me enamoro de mi trabajo y lo disfruto, lo voy a hacer mejor, sino lo hago por salir del paso" (informante 1). El sistema educativo costarricense tiene un reclutamiento de su personal docente por titulación, lo que no garantiza la vocación. Es por ello por lo que uno de los mayores obstáculos, precisamente, recae en los docentes, quienes en algunos casos estudiaron educación por facilidades de acceso a las universidades, pero no por vocación; esto limita el trabajo colaborativo indispensable en un centro educativo que trabaje para la justicia social. Sin embrago, la directora también aporta que a pesar de que algunos de sus docentes llegan a la institución sin vocación, "Con el paso del tiempo, con dinámicas constantes se logra que estos docentes puedan pensar y actuar diferente, pero se toma su tiempo" (informante 1). En este sentido, se destaca el estilo de liderazgo, el cual transforma condiciones para una labor comprometida con cerrar brechas sociales.

Uno de los elementos de análisis que surgió como un obstaculizador es la participación de las familias, a lo que la directora dice que "algunas 
familias no son conscientes que lo que hacen a sus hijos es lo que tendrán en el futuro. Hay maltrato, abandono e indiferencia. Una desea tener varitas mágicas para cambiar algunos casos" (informante 1). Los contextos de vulnerabilidad social son sujetos de este tipo de convivencias y es uno de los retos más grandes que asume el centro educativo.

En lo tocante a los obstáculos, expresa el director de la unidad pedagógica que el sistema de evaluaciones, al concluir los estudios para la secundaria, que realiza el Ministerio de Educación Pública, atenta contra una filosofía de inclusión, ya que plantea una valoración "masiva" que no reconoce particularidades de las poblaciones. Se aplica un examen para todos los estudiantes costarricenses, sin importar contexto cultural, geográfico, social, si vienen de clase media, alta o en pobreza extrema (informante 2).

\section{Formación como líderes en justicia social}

Finalmente, se cuestiona a la directora de preescolar sobre la formación como líder para la justicia social y surgen dos elementos sustantivos: la experiencia de vida y la formación académica.

La directora remite a su experiencia de vida, que lejos de ser un modelo, para ella, de justicia social, fue todo lo contrario, tuvo una infancia en la cual las injusticias fueron parte de su diario vivir: "El enfrentarse a las situaciones donde se toma consciencia de lo que hay que hacer y anteponer lo ético no siempre es fácil" (informante 1). El deseo de justicia, equidad e igualdad se fue desarrollando con las experiencias de vida en el núcleo familiar y luego lo llevó al ámbito académico.

Para ella, actuar de manera ética es parte de su compromiso "Los valores que uno tenga y los valores que tenga la organización, siempre tendiendo como clave el bien común y no individual, el director puede pasar desapercibido, que hagan las cosas bien es lo que importa" (informante 1). Lo anterior denota un estilo de liderazgo basado en valores y participativo, en el que prevalece el bien común sobre lo individual. También indicó que ella aprende de todo, tanto de la conversación con un niño como de la lectura de un libro o una película; tiene en su vida una condición de aprendiente.

Desde la experiencia del director de la unidad pedagógica, su formación como líder en justicia social tiene sus inicios en su infancia en la ciudad de Panamá, donde asistía a una institución educativa de clase alta 
y la metodología que utilizaban sus maestros hacía una división entre los estudiantes más brillantes y los menos capaces. Él estaba entre los estudiantes más brillantes; sin embargo, sus hermanos estaban en el grupo de los menos, lo que provocaba mucha frustración y deseos de hacer algo para cambiar esa situación. Indica: "al grupo de los menos capaces les decían brutos y eso me hacía sentir muy mal. Existía apatía por parte de mis hermanos hacia la escuela y sus docentes, yo le ayudaba a mis hermanos y a las personas del barrio a explicarles los temas de estudio; para mí era muy sencillo, porque tenía facilidad para explicar, el comportamiento de ellos era terrible pero aun así yo les ayudaba y veía el desequilibrio en la parte de cómo enseñar; todo era negativo en la escuela" (informante 2).

La experiencia de la infancia puede marcar positiva o negativamente a las personas, en el caso del director, el vínculo afectivo que tenía con sus hermanos, quienes eran maltratados por sus docentes al utilizar metodologías que no respondían a sus necesidades, generó un espíritu de apoyo en él hacia los más necesitados.

Otro evento que marcó su vida fue una tragedia familiar y una enfermedad del corazón que se le declaró cuando cursaba sus estudios en la facultad de medicina en Costa Rica. De un momento a otro, su vida dio un giro, se quedó sin apoyo económico para culminar sus estudios de medicina y con una enfermedad grave en el corazón. Estas circunstancias lo llevaron a replantearse sus metas y empezar desde una condición económica que desconocía, lo cual lo sensibilizó con las personas que son marginadas, excluidas.

Estas experiencias lo han llevado a ser un defensor de los más necesitados y considera que desde la educación se pueden liberar mentes y potenciar las capacidades de las personas para que "no sigan castigándolas con el látigo de la injusticia" (informante 2) y puedan tener una vida digna, sin ser excluidas por su condición de pobreza, color de su piel, credo o género. "Muchos líderes deben de tener la experiencia de choque para aprender lo que es importante en la vida y que uno está en este mundo para hacer un lugar mejor para todos" (informante 2).

\section{Discusión de resultados}

En un estudio publicado por Silva et al. (2017), se retoman los aportes realizados por Cribb y Gewirtz (2003) y Priest, Woods y Roberts (2013), los cuales son congruentes con los resultados de los dos 
casos analizados en relación con la concepción que se tienen de justicia social, ya que ambos directores consideran que la educación de calidad es un derecho para todos, que se debe tener acceso a ella sin discriminación por cultura, etnia o credo. La educación debe brindar una oferta curricular que permita el desarrollo de las capacidades de las personas, para que puedan acceder a una mejor calidad de vida.

La visión de justicia que tienen los participantes es de reconocimiento de sus estudiantes como sujetos de derecho, que no pueden ser marginados por su condición de migrantes, en el caso de la directora de preescolar, o por su condición de necesidades educativas especiales, en el caso del director de la unidad pedagógica. Estas nociones coinciden con la estructura de justicia social que hacen Murillo y Hernández (2014).

Ambos directores asumen una posición de un liderazgo transformacional, aunque desde diferentes realidades; uno desde estudiantes migrantes y en condición de pobreza y el otro desde el sentir de las familias de estudiantes excluidos por el sistema educativo. Shields (2004) se refiere a este tipo de liderazgo como aquel que gestiona procesos para promover cambios sociales, oponiéndose al status quo que perpetúa las condiciones de injusticia para ciertos sectores sociales.

En cuanto al accionar de los dos líderes en justicia social, hay un trabajo intencionado y direccionado a la transformación social desde los espacios permitidos por el sistema; no son procesos revolucionarios, sino más bien evolutivos, en los cuales hay una labor de convencimiento para ganar adeptos a su visión. No existe imposición de sus ideas, sino un liderazgo democrático que hace un llamado a la sensibilidad de sus colaboradores para buscar juntos soluciones viables a los problemas que enfrentan.

Por lo anterior, se considera que el estilo de liderazgo del directivo escolar es uno de los elementos clave para la justicia social, máxime, en un contexto educativo como el costarricense, en el que, por más de cien años, se ha intentado sostener un Estado democrático, y en donde la educación es uno de los pilares fundamentales que sostienen el orden social preestablecido.

El director de la unidad pedagógica hace esfuerzos, con su equipo de trabajo, para brindar alternativas de atención en la oferta curricular, con el propósito de responder a las necesidades de cada estudiante. Promulgan una atención que trasciende los contenidos de los programas de estudio e intentan favorecer una formación integral, prestando especial interés en el componente emocional. Estas prácticas de liderazgo 
son parte del planteamiento teórico de Nussbaum (2010), quien aporta que la justicia social debe desarrollar las capacidades básicas de las personas para poder llevar una vida plena, centrada en sus necesidades y características propias. Desde este abordaje, se pueden identificar once capacidades básicas: vida, salud física, integridad corporal, sentidos, imaginación y pensamiento, emociones, juego, razón práctica, afiliación, control sobre el propio entorno y respeto a otras especies. La formación integral conforma un elemento relevante de análisis para la justicia social, ya que es a través de una enseñanza que atienda las necesidades específicas de los estudiantes como se pueden desarrollar las capacidades de las personas.

Lo anterior hace hincapié en escuelas que respondan a un enfoque inclusivo como lo mencionan Murillo et al. (2010). Desde este enfoque, se enriquece una oferta curricular que celebra la diversidad y abre espacios para aquellos estudiantes que no se acoplan a metodologías masificantes.

En relación con el caso de la directora de preescolar, su atención está centrada en la igualdad de oportunidades para sus estudiantes, independientemente de su condición de familias migrantes o de pobreza en algunos casos extrema. Ella hace esfuerzos, en colaboración con los integrantes del personal del centro educativo, para brindarles a sus alumnos condiciones dignas de una oferta educativa de mejor calidad; incluye el desarrollo de capacidades cívicas, en cuanto a la participación democrática en diversas actividades, otorgándoles el poder para la toma de decisiones. Utilizan cualquier espacio de aprendizaje para potenciarles el reconocimiento como sujetos de derecho en un contexto democrático. Entre algunas acciones que se vinculan a los espacios de participación democrática se puede mencionar que la comunidad estudiantil elige el nombre de los animales que cuida diariamente en el centro educativo (granja). Además, los niños participan de procesos de reciclaje para generar conciencia ambiental; cuentan con la asignación semanal de responsabilidades para los espacios de juego, en donde deben asumir roles inclusivos y de protección para sus compañeros. Por otro lado, también se les brinda a los estudiantes la oportunidad de elegir el taller ${ }^{5}$ al que desean asistir, así que cuentan con espacios en los cuales se promueven talentos como danza, artes marciales, fútbol, capoeira, computación, inglés, entre otros.

5 Estos talleres no son parte del sistema público para el nivel de preescolar, por lo que es una gestión del centro educativo con organismos de apoyo. 
Lo descrito se relaciona con los aportes teóricos que proponen Cribb y Gewirtz (2003), quienes mencionan cuatro tipos de justicia social. La primera, la económica, se ve reflejada en el caso de la directora, cuando pretende garantizar la igualdad de oportunidades sin importar raza, credo o condición de género. Por otro lado, la justicia cultural favorece el reconocimiento del individuo como parte de un contexto sociocultural, con valores propios de su grupo social. Hay una legitimación esos valores que responden a la condición de familias migrantes. Los padres y las madres son integrados en procesos de aprendizaje con sus hijos. Se visualiza, también, una justicia asociativa, que promueve la participación equitativa, dando vida, en los salones de clase, a los postulados de los contextos democráticos. La formación de ciudadanos es una tarea de todos y se debe promover en los diferentes niveles del sistema educativo. Finalmente, se refleja, en este caso, una justicia para el desarrollo, vista claramente en la oferta educativa que sobrepasa lo preestablecido por el sistema público y que busca el desarrollo de las capacidades de los estudiantes y sus familias, para una mejor calidad de vida.

En estos dos casos de análisis desarrollados en el contexto educativo costarricense, se refleja una conexión estrecha con los aportes de Montané (2015), quien hace un recorrido histórico del término justicia social y lo vincula con la educación, caracterizando que la primera, aplicada a los procesos educativos, debe contemplar en su accionar conceptos como legitimidad, dignidad, justicia, libertad, reconocimiento, participación y capacidad. Se considera que en ambos casos los líderes seleccionados para el estudio hacen esfuerzos con el afán de pasar del discurso a la práctica y de lograr que en sus centros educativos se puedan desarrollar capacidades, para que sus estudiantes puedan tener una participación social que les permita el acceso a una mejor calidad de vida a través de la educación.

Los factores que obstaculizan el liderazgo para la justicia social, según las personas informantes, se centran en la vocación docente, la participación de las familias en los procesos de formación y el sistema de evaluación del Ministerio de Educación Pública. Estos hallazgos coinciden con los aportes de Nussbaum (2010), quien asume a la persona desde una integralidad indivisible, que requiere el apoyo de los docentes, las familias, así como de políticas inclusivas, las cuales garanticen una formación que desarrolle las capacidades necesarias para 
una mejor calidad de vida, tal y como indica Bolivar (2015), pensando en trascender a una cultura educativa de excelencia.

En cuanto a la formación como líderes, en los casos estudiados, se refiere a la experiencia de vida, enmarcada en los vínculos familiares y desde la emocionalidad que les provoca las injusticias desde su infancia y a través de los años. Ambos directores, en su edad adulta, eligieron un camino como líderes en justicia social, haciendo realidad y favoreciendo el pensamiento freiriano en la búsqueda de la dignidad de las personas y la legitimidad tanto de los contextos como de los saberes.

\section{Conclusiones}

El sentido de justicia social se relaciona con el reconocimiento del estudiantado como sujetos de derecho y con el desarrollo de sus capacidades, a través de los procesos de enseñanza y aprendizaje que potencia el centro educativo. La percepción del estudiante como un ser integral y capaz de transformarse desde los procesos educativos es un principio que moviliza el accionar de ambos directores.

Las acciones desarrolladas por los líderes de justicia social se asocian a los espacios de participación democrática de la comunidad estudiantil, a la búsqueda de soluciones para solventar sus necesidades en los procesos de aprendizaje. De esta manera, se les brinda mayores oportunidades en el desarrollo de sus capacidades y, por ende, se favorecen las posibilidades para una mejor condición de vida.

Los factores que limitan el trabajo de los líderes para la justicia social se vinculan a las estructuras normativas del sistema educativo y al apoyo limitado de las familias que vienen de contextos en vulnerabilidad social, las cuales se movilizan en círculos de pobreza y agresiones intrafamiliares, dificultando procesos que el centro educativo desea favorecer para que la comunidad estudiantil se vea inmersa en procedimientos inclusivos.

El aprendizaje de los líderes para la justicia social, en ambos casos, se desarrolló desde temprana edad. Los contextos, las experiencias de vida y los vínculos afectivos destacan como elementos importantes en su formación, seguidos por las oportunidades de formación profesional a las cuales tienen acceso.

Los líderes para la justicia social están en constante contacto con la comunidad educativa, desarrollan una escucha atenta ante las 
necesidades de sus integrantes y son capaces de tomar riesgos que, en algunos casos, no son compatibles con las normativas del sistema, pero que son necesarios para generar transformaciones de espacios más inclusivos. Esto los convierte en pioneros de innovaciones educativas.

Los directivos escolares son personas clave para promover la justicia social en todas las acciones que se promuevan desde el centro educativo. Estas últimas deben ser construidas con el colectivo docente, para instaurar una cultura organizacional que favorezca la justicia social.

\section{Referencias}

Barquero, M. A. y Montero, M. (julio-diciembre, 2013). Análisis comparativo de la gestión educativa como agente de cambio e innovación ante los complejos ambientes educativos, caso de las organizaciones: Colegio Nuevo Mundo y Colegio Técnico Profesional Piedades Sur, San Ramón. Revista Gestión de la Educación, 3(2), 43-67. Recuperado de http://revistas.ucr.ac.cr/index. $\mathrm{php} / \mathrm{gestedu} / \mathrm{article} / \mathrm{view} / 10648 / 10044$

Bisquerra, R. (Coord.). (2014). Metodología de la investigación educativa. Madrid, España: Editorial La Muralla.

Bolívar, A. (2015). Justicia social y equidad escolar. Una revisión actual. Revista internacional de educación para la justicia social, l(1). Recuperado de https://revistas.uam.es/riejs/article/view/308

Bourdieu, P., Passeron, J. C., Melendres, J. y Subirats, M. (1981). La reproducción: elementos para una teoría del sistema de enseñanza. Barcelona: Laia.

Contreras, F. y Barbosa, D. (2013). Del liderazgo transaccional al liderazgo transformacional: implicaciones para el cambio organizacional. Revista virtual universidad católica del norte, 2(39), 152-164. Recuperado de http://revistavirtual.ucn.edu.co/index. $\mathrm{php} /$ RevistaUCN/article/view/433

Cribb, A. y Gewirtz, S. (2003). Towards a sociology of just practices. En C. Vincent (ed.), Social justice, education and identity (pp. 15-30). New York: Routledge Falmer.

Fernández, J. M. y Hernández, A. (2013). Liderazgo directivo e inclusión educativa: Estudio de casos. Perfiles educativos, 35(142), 27-41. Recuperado de http://www.scielo.org.mx/scielo. php?script=sci_arttext\&pid=S0185-26982013000400003 
Freire, P. (2005). Pedagogía del oprimido. México: Editorial siglo XXI. Garbanzo, G. y Orozco, V. H. (2007). Desafíos del sistema educativo costarricense: Un nuevo paradigma de la administración de la educación. Revista Educación, 31(2), 95-110. Recuperado de http:// revistas.ucr.ac.cr/index.php/educacion/article/view/1246/1309

Hernández, R., Fernández, C. y Baptista, P. (2010). Metodología de la investigación. México D. F., México: Editorial Mc Graw Hill.

McKenzie, K. B., Christman, D. E., Hernández, F., Fierro, E., Capper, C. A., Dantley, M., ... y Scheurich, J. J. (2008). From the field: A proposal for educating leaders for social justice. Educational Administration Quarterly, 44(1), 111-138.

Molano, A. D. (2016). La gestión educativa: Hacia la optimización de la formación docente en la educación superior en Colombia. Sophia, 12(1), 55-70.

Montané, A. (2015). Justicia social y educación. RES. Revista de Educación Social, 20, 1-21. Recuperado de http://www.eduso.net/ res/winarcdoc.php?id $=542$

Murillo, F. J., Krichesky, G., Castro, A., y Hernández-Castilla, R. (2010). Liderazgo para la inclusión escolar y la justicia social. Aportaciones de la investigación. Revista latinoamericana de educación inclusiva, 4(1), 169-186. Recuperado de http://ctescolaresmich.gob.mx/documentos/LIDERAZGO_PARA_LA_INCLUSION.pdf

Murillo, F. J. y Hernández, R. (2014). Liderando escuelas justas para la justicia social. Revista Internacional de Educación para la Justicia Social, 3(2). Recuperado de https://revistas.uam.es/riejs/ article/view/337

Nussbaum, M. C. (2010). Sin fines de lucro. Por qué la democracia necesita de las humanidades. Madrid: Katz Editores.

Shields, C. M. (2004). Dialogic leadership for social justice: Overcoming pathologies of silence. Educational Administration Quarterly, 40(1), 109-132.

Silva, P., Slater, C. L., López Gorosave, G., Cerdas, V., Torres, N., Antunez, S. y Briceno, F. (2017). Educational leadership for social justice in Costa Rica, Mexico, and Spain. Journal of Educational Administration, 55(3), 316-333.

Woods, P. A. (2005). Democratic leadership in education. London: Sage. 
